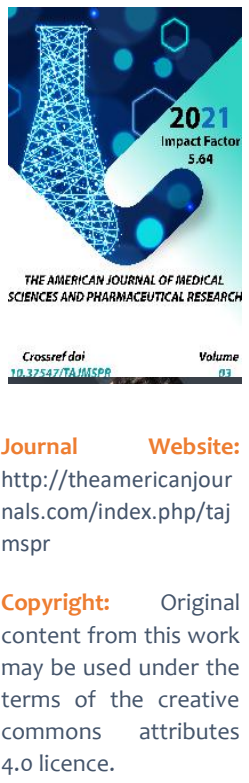

\title{
Prevention \& Treatment Of Cardiovascular Diseases
}

\author{
Dr. Imran Aslam \\ Department Of Pharmacology, Samarkand State Medical Institute, Samarkand, Uzbekistan \\ Yuldashev Soatboy Jiyanboyevich \\ Department Of Pharmacology, Samarkand State Medical Institute, Samarkand, Uzbekistan
}

Abdurakhmanova Zamira Ergashboevna

Department Of Pharmacology, Samarkand State Medical Institute, Samarkand, Uzbekistan

\section{ABSTRACT}

Cardiovascular disease is a significant problem that humans have always faced, affecting thousands of people's lives and health and taking the lives of many people. Many medical institutions and researchers have regarded it as a significant problem in overcoming the cardiovascular disease. 1 Much attention has been paid, so the prevention and treatment level in this area has also been rapidly improved. However, cardiovascular disease still cannot be prevented or treated fundamentally, and it is still a significant danger to human health. All people still hope for breakthrough results in cardiovascular disease.2 This article analyzes the prevention and treatment of cardiovascular diseases, and has obtained a series of practical and reliable conclusions.

\section{KEYWORDS}

$\begin{array}{lll}\text { Prevention } \quad \text { and } & \text { treatment; } & \text { Cardiovascular }\end{array}$

\section{INTRODUCTION}

Cardiovascular diseases (CVD) are the diseases of heart or blood vessels present in heart or body. ${ }^{3}$ It is associated with heart and blood vessels but it can also damage arteries in the kidney, brain, lungs, stomach, and other organs in the body. ${ }^{4}$ It is main cause of death worldwide. Once a cardiovascular disease occurs, it will significantly impact daily work, affect everyday life, and greatly impact the patient's psychology and physiology. ${ }^{5}$ The high cost of treating the cardiovascular disease will bring a lot to patients, a significant economic burden. New methods to prevent and treat cardiovascular diseases, cardiovascular and cerebrovascular diseases do not bother humankind. ${ }^{6}$ There are mainly 
mainstream trends in the treatment of cardiovascular diseases. Western medicine treatment methods. These methods have been developed separately and have achieved good development. ${ }^{7}$ They have sound effects on cardiovascular diseases. The ways each has its own merits. How to make up for the advantages of treatment methods to achieve a better curative impact on cardiovascular diseases is the current research direction of many cardiovascular disease researchers. ${ }^{8}$ Still, medical research cannot rely on theory and needs to be repeated experimentally. The characteristics and methods of experiments have also become essential research points for researchers.

\section{LITERATURE REVIEW}

Nearly 84 million people in the United States suffer from cardiovascular disease (CVD), with nearly half of those under the age of $60 .{ }^{9}$ According to the researchers, men have a higher lifetime risk of developing CVD than women in most age groups. ${ }^{10}$ Since subclinical atherosclerosis develops early in life, four factors linked to increased cardiovascular risk in young men should be established in order to improve effective risk-reduction strategies. Males between the ages of $18-25$ are considered emerging adult males. ${ }^{11}$ Because of their independence, lack of parental supervision, and financial insecurity, they are more likely to engage in CVD danger behaviours. Cardiovascular risk factors that develop through puberty and early adulthood have been found to persist into later adulthood, raising the risk of CVD. ${ }^{12}$ Causes of

\section{Disease:}

It can be caused by high blood pressure, high cholesterol, overweight, and obesity. Some other factors like the use of unhealthy diet, physical inactivity, excessive use of alcohol, and smoking. ${ }^{3-15}$

\section{Types of Disease:}

In the present study cardiovascular disease is studied that can affect the heart and blood vessels. It involves Coronary artery disease and it can also be called as coronary heart disease and ischemic heart disease.

- Peripheral arterial disease: Disease of Peripheral arteries supply blood to the arms and legs got disease due to in vessels ${ }^{13}$

- Cerebrovascular disease: It can affect blood vessels that are specified to transfer blood to the brain. ${ }^{14}$

- Aortic aneurysm: it is also a cardiovascular disease. $^{14}$

- Cardiomyopathy: it is a disease that can affect the muscle of the heart. ${ }^{15}$

- Hypertensive heart disease -This heart disease is secondary to hypertension and high blood pressure.

- Heart failure: It occurs due to the inefficiency or failure of the heart to supply a sufficient amount of blood to the tissue in order to meet its requirements. ${ }^{16}$

- Pulmonary heart disease: These diseases involve failure of the right side of the heart that can affect the lungs. ${ }^{17}$

- Cardiac dysrhythmias: It occurs due to the abnormalities of heart rhythms.

- Inflammatory heart disease

- Eosinophilic myocarditis: inflammation of the myocardium caused by pathologically activating the eosinophil white blood cells.

- Congenital heart disease: Problems in heart malformation that occurs during the time of birth. ${ }^{18}$ 


\section{Clinical diagnosis}

The main predictors of coronary artery disease in humans due to tobacco smoking, diabetes mellitus, and hyperlipidemia. ${ }^{19}$

\section{Overview of clinical trials}

Clinical trials are one type of clinical research. Due to the nature of trials, to conduct clinical trials, search people with specific characteristics, and use them as samples for testing, it is important to verify the treatment method's actual effect. The new treatment method's substantial curative effect that the masses are not identified. can also be observed through this method. The public can also trust the actual objective test data for the treatment method, which has been applied and popularized among patients, and some modifications can be made. , Can be provided to more people. Clinical trials can also help eliminate misunderstandings in many medical mistakes and clarify patients' interests, which is superficially beneficial. Can assist the treatment method not to be deceived. ${ }^{20}$

The country has a strict set of procedures for drug clinical trials. Generally, it is necessary to select drugs with batch numbers and passing certificates that have been approved by the country after submitting an assessment and obtaining a response. For drugs that are not on the market, the research staff must have relevant materials to prove their legitimacy. The state has approved it, and the drug is qualified, and it cannot be used on a large scale. Clinical trials have inevitable risks. It is necessary to fully guarantee the fairness of the experiments and ensure the maximum level of tranquility to avoid shadowing patients' minds. ${ }^{21}$
To effectively prevent cardiovascular diseases, medical researchers have launched many clinical experiments on cardiovascular diseases. In the trial, the accuracy and compliance of the trial results must be emphasized, but the solid foundation for its clinical implementation must be laid. The results of the attempts should have specific statistical significance. Such talents and accurate estimation of the sampling deviation should be regarded as a new method of clinical treatment of Western treatment methods regardless of the quality of the attempt. $^{22}$

Cardiovascular and cerebrovascular disease is currently the primary disease threatening human well-being.

Its characteristics have "five highs":

$\checkmark \quad$ High incidence rate

$\checkmark \quad$ High disability rate

$\checkmark$ High incidence of multiple organ dysfunction

$\checkmark \quad$ High sudden death rate

$\checkmark \quad$ High death rate

Therefore, people are taking it more and more squarely. Most of the pathological examples are structural ischemia, while a few are bleeding.

Ischemic vascular disease is categorized into acute and chronic form.

Its precise etiology can be divided into six categorize.
1. Arterial softening plaque composition.
2. Plaque division and shedding. 
3. Thrombus composition.

4. Falling off old blood clots.

5. Decreased blood viscosity.

6. Vasospasm.

\section{Diagnosis}

\section{For brain diseases:}

(1) Use CT or MRI to scan the brain structure: it can quickly and accurately understand the diseased nature, location, size and provide accurate and helpful guidance for clinical treatment. ${ }^{23}$

(2) Add MRI cerebrovascular imaging or CT plus enhancer: it can understand the blood flow status of cerebrovascular and the location and level of vascular infarction, and provide guidance for follow-up treatment and prognosis; this inspection method can also be used for carotid artery (carotid artery). Vertebral artery) check to confirm whether there is softening and plaque formation. ${ }^{24}$

(3) B-ultrasound cervical blood vessel examination: able to understand whether there are plaques in bilateral carotid arteries, vertebral arteries, subclavian arteries, and other blood vessels, as well as the plaque nature and narrowness, whether it affects blood activity, and whether there are plaques. The ability to shed to cause acute cerebral infarction is significant in examining the pathological transformation environment before and after medication. ${ }^{25}$

\section{Changes to heart disease}

(1) Application of electrocardiogram: accurate positioning and qualitative diagnosis of various heart rate abnormalities, reference diagnosis of myocardial ischemia and myocardial infarction can also be made to provide real-time and precise. ${ }^{26}$

(2) Cardiac B-ultrasound: This ultrasound is able to recognize the actual size of the heart cavity, the function of the valves, the thickness of the myocardium, whether the layout of the myocardium is abnormal, the state of myocardial diastolic and systolic function, and the evaluation of cardiac function. ${ }^{27}$

(3) Coronary angiography: It is helpful in the efficient diagnosis of blood flow, vascular softening, plaque composition, and stenosis of the blood vessels of the myocardium. It is the golden standard for diagnosing coronary pedicles and is accurate and useful. The supply of treatment is reliable and guaranteed. to the aorta of the whole body. ${ }^{28}$

(1) Application of angiography: such as thoracic, abdominal arteries, iliac arteries, limb arteries, etc., to check the softening of blood vessels, plaque composition, vascular dissection, degree of vascular stenosis, and blood flow conditions, which can provide helpful guidance for treatment. ${ }^{29}$

\section{(2) Application of B-ultrasound exploration:} whether there are plaques, stenosis, thrombus, and blood flow in the thoracic, abdominal arteries, iliac arteries, and limb arteries, which is helpful for medical supply and static image guidance. ${ }^{30}$

Also: In recent years, the application of intravascular ultrasound (IVUS) technology has become more familiar with vascular status, plaque layout, and thrombosis and can make more accurate judgments about the size, size, and severity of plaques and thrombus. ${ }^{31}$ 


\section{Prevention and treatment}

\section{(1) Cerebrovascular disease}

It can be installed with a stent, or vascular media plaque dissection, which can treat insufficient blood supply to the brain and prevent plaque shedding and acute cerebral infarction. Also, according to the different conditions of the disease, craniotomy can be performed in real-time to treat various cerebrovascular diseases. ${ }^{32}$

\section{(2) Cardiovascular disease}

Cardiac arrest: for patients with acute myocardial infarction and ventricular fibrillation, cardiac defibrillation can be performed to wake up the heart; plaque shedding causes acute myocardial infarction: the infarct can be removed by surgery under the guidance of CT/B ultrasound; blood vessel narrow and severe Patients: implantable stents to dredge blood vessels; complete infarct blood vessels: surgical bypass surgery can be performed to recanalize the blood vessels. Severe conduction stagnation: wild pacemaker can be installed. Frequent atrial fibrillation: microwave dissolution can also be used to cure atrial fibrillation completely. ${ }^{33}$

\section{RELEVANCE OF THE STUDY}

The value of CVD avoidance is widely acknowledged. ${ }^{34,35}$ International recommendations emphasise the potential, effectiveness, and potential future benefits. ${ }^{36}$ If they minimise overall resource use and demand, effective preventative strategies can help to manage escalating health-care costs and encourage the affordability of health-care programmes. ${ }^{37}$ The case for avoidance, on the other hand, is not entirely clear. In clinical practise, there is a possible discrepancy between prevention and therapies used to relieve illness or mitigate symptoms, in addition to realistic questions of implementation and assessment. ${ }^{38}$ Prevention has a range of drawbacks, including the fact that it can cause distress in otherwise stable individuals and that preventative treatments can be dangerous. ${ }^{39}$ Preventative measures must be weighed against the opportunity costs of adopting them, particularly if they draw scarce healthcare services away from treatment. Indeed, others contend that avoidance does not take precedence over basic medical treatment. ${ }^{5}$ Despite these critiques, it is important to remember that pharmaceutical treatment has drawbacks (side effects, polypharmacy, decreased quality of life, expense, and so on), and it is difficult to overlook the significant possible health benefits that prevention can provide. ${ }^{40-43}$

The current study is focusing on the prevention and treatment of cardiovascular diseases.

\section{PURPOSE OF THE STUDY}

This study aims to explore the prevention and treatment of cardiovasular disease. Cardiovascular disease (CVD) is the leading cause of mortality and morbidity worldwide and, crucially, may be preventable through the modification of cardiovascular risk factors. ${ }^{40}$ This work can be useful for the number of individuals suffering from CVD, residents, and the individuals who might also want to research this and other related subjects.

\section{METHODS OF RESEARCH}

Analysis of literature, publications related to prevention and treatment of cardiovasular disease. In this study, have gathered data on a particular subject written by academics and 
writers from published journals, related websites, and books. Researchers used several sources and websites to find papers, together with Google scholar and take a look at Gate structures. . In the current study, using the literature review as a methodology, prevention and treatment of cardiovasular disease; systematic, semi-systematic, and integrative methods were used to define knowledge gaps within the literature. The literature has been reviewed from the most recent articles related to the prevention and treatment of cardiovasular disease. The current study is systematic review based study.

\section{RESULT}

After reviewing a number of publications, the current study concluded that prevention and treatment of cardiovascular disease. The findings of this study have been based on previous research on the subject. Gaps in CVD prevention and treatment awareness among the general public and health care practitioners, risk misperceptions, lower the level of hypertension as well as the cholesterol screening, low levels of physical activity and cardiovascular fitness, overweight and obesity are the causes of CVD, the education regarding the prevention of CVD should be increased. The study findings present a challenge to health care professionals and patients to intervene by delivering thorough education about CVD prevention across multiple forms of communication, support pathways, and increasing creativity in CVD treatment and prevention techniques. Furthermore, the findings indicate that participants in future studies will benefit from having access to therapies that increase their knowledge and understanding of CVD, as well as help their attempts to live a healthier lifestyle.

\section{CONCLUSION}

Ongoing research revealed the development of western medicines in the treatment of cardiovascular diseases. In addition to them, different technologies like Cardiac Bultrasound, Coronary angiography, and electrocardiogram have been developed. But research should continue to focus on the development of new technologies including some specific procedures or surgery for the prevention and treatment of heart diseases. Researchers should focus on the innovation of stem cell transplantation and strengthen the clinical and quality control of comprehensive medical research.

\section{REFERENCES}

1. Davies, S. W. (2001). Clinical presentation and diagnosis of coronary artery disease: stable angina. British medical bulletin, 59(1), 17-27.

2. Davies, S. W. (2001). Clinical presentation and diagnosis of coronary artery disease: stable angina. British medical bulletin, 59(1), 17-27.

3. Ghuran, A. V., \& Camm, A. J. (2001). Ischaemic heart disease presenting as arrhythmias. British medical bulletin, 59(1), 193-210.

4. Bailey, R. L., Thuppal, S. V., Sherif, K. D., Denby, N., Steinbaum, S. R., Haycock, B., ... \& von Schacky, C. (2019). No Relationship Between Serum $25(\mathrm{OH})$ Vitamin D Concentrations and Perceptions of Vitamin D Dietary Intake Adequacy in US and German Adults Not Using Dietary Supplements. In Nutritional Influences on Bone Health (pp. 247-256). Springer, Cham. 
5. Daull, P., Jeng, A. Y., \& Battistini, B. (2007). Towards triple vasopeptidase inhibitors for the treatment of cardiovascular diseases. Journal of cardiovascular pharmacology, 50(3), 247-256.

6. Blanco-Colio, L. M. (2014). TWEAK/Fn14 axis: a promising target for the treatment of cardiovascular diseases. Frontiers in immunology, 5, 3.

7. DiNicolantonio, J. J., Liu, J., \& O'Keefe, J. H. (2018). Magnesium for the prevention and treatment of cardiovascular disease.

8. Bale, J. R., Ryan, T. J., Reddy, K. S., \& Howson, C. P. (Eds.). (1998). Control of cardiovascular diseases in developing countries: research, development, and institutional strengthening. National Academies Press.

9. Beaglehole, R., Saracci, R., \& Panico, S. (2001). Cardiovascular diseases: causes, surveillance and prevention. International Journal of Epidemiology, 30(suppl_1), S1.

10. Prabhakaran, D., Jeemon, P., \& Roy, A. (2016). Cardiovascular diseases in India: current epidemiology and future directions. Circulation, 133(16), 1605-1620.

11. Celermajer, D. S., Chow, C. K., Marijon, E., Anstey, N. M., \& Woo, K. S. (2012). Cardiovascular disease in the developing world: prevalences, patterns, and the potential of early disease detection. Journal of the American College of Cardiology, 6o(14), 1207-1216.

12. Mark, D. B., Van de Werf, F. J., Simes, R. J., White, H. D., Wallentin, L. C., Califf, R. M., \& Armstrong, P. W. (2007). Cardiovascular disease on a global scale: defining the path forward for research and practice. European heart journal, 28(21), 2678-2684.

13. Hancock, S. L., Tucker, M. A., \& Hoppe, R. T. (1993). Factors affecting late mortality from heart disease after treatment of Hodgkin's disease. Jama, 270(16), 19491955.

14. Fonarow, G. C., Gawlinski, A., Moughrabi, S., \& Tillisch, J. H. (2001). Improved treatment of coronary heart disease by implementation of a Cardiac Hospitalization Atherosclerosis Management Program (CHAMP). The American journal of cardiology, 87(7), 819822.

15. Collins, R., \& MacMahon, S. (1994). Blood pressure, antihypertensive drug treatment and the risks of stroke and of coronary heart disease. British medical bulletin, 50(2), 272-298.

16. Rashkind, W. J. (1983). Transcatheter treatment of congenital heart disease. Circulation, 67(4), 711-716.

17. Capewell S, Allender S, Critchley J, LloydWilliams F, O'Flaherty M, Rayner M, et al. Modelling the UK burden of Cardiovascular Disease to 2020. London: Cardio and Vascular Coalition and the British Heart Foundation, 2008.

18. British Heart Foundation. Stroke and your heart. [cited 2014 4th September]; Available from: http://www.bhf.org.uk/hearthealth/conditi ons/stroke.aspx.

19. Levy D, Kannel WB. Cardiovascular risks: new insights from Framingham. American Heart Journal. 1988;116:266-72.

20. Reddy KS, Satija A. The Framingham Heart Study: impact on the prevention and control of cardiovascular diseases in India. Progress in cardiovascular diseases. 2010;53:21-7.

21. van den Hoogen $P C W$, Feskens EJM, Nagelkerke NJD, Menotti A, Nissinen A, Kromhout D. The relation between blood pressure and mortality due to coronary 
heart disease among men in different parts of the world. New England Journal of Medicine. 2000;342:1-8. 203

22. Rockhill B, Newman B, Weinberg C. Use and misuse of population attributable fractions. American Journal of Public Health. 1998;88(1):15-9.

23. Smulders YM, Thijs A, Twisk JW. New cardiovascular risk determinants do exist and are clinically useful. European heart journal. 2008;29:436-40.

24. Mackenbach JP, Cavelaars AEJM, Kunst $A E$, Groenhof F. Socioeconomic inequalities in cardiovascular disease mortality: an international study. European heart journal. 2000;21:1141-51.

25. DeWilde S, Carey IM, Richards N, Whincup $\mathrm{PH}$, Cook DG. Trends in secondary prevention of ischaemic heart disease in the UK 1994-2005: use of individual and combination treatment. Heart. 2008;94:83-8.

26. Rose G. Rose's Strategy of Preventive Medicine. Oxford: Oxford University Press; 2008. 209 92. Rose G. Sick individuals and sick populations. International Journal of Epidemiology. 2001;30:427-32.

27. Di Castelnuovo A, Costanzo S, Bagnardi V, Donati MB, lacoviello L, de Gaetano G. Alcohol dosing and total mortality in men and women: an updated meta-analysis of 34 prospective studies. Archives of Internal Medicine. 2006;166:2437-45.

28. Charlton BG. A critique of Geoffrey Rose's 'population strategy' for preventive medicine. Journal of the Royal Society of Medicine. 1995;88:607-10.

29. Burton H, Sagoo GS, Pharoah P, Zimmern RL. Time to revisit Geoffrey Rose: strategies for prevention in the genomic era? Italian Journal of Public Health. 2012;9(4):e8665.
30. Hingorani A, Hemingway $\mathrm{H}$. How should we balance individual and population benefits of statins for preventing cardiovascular disease? BMJ. 2011;342:c6244.

31. Jackson R, Lynch J, Harper S. Preventing coronary heart disease. BMJ. 2006;332:617-8.

32. Cobiac LJ, Magnus A, Lim S, Barendregt JJ, Carter R, Vos T. Which interventions offer best value for money in primary prevention of cardiovascular disease? PLoS ONE. 2012;7(7):e41842.

33. Ebrahim S, Taylor F, Ward K, Beswick A, Burke M, Davey Smith G. Multiple risk factor interventions for primary prevention of coronary heart disease. Cochrane Database of Systematic Reviews. 2011;DOI: 10.1002/14651858.CD001561.pub3.

34. de Cates AN, Farr MRB, Wright N, Jarvis $M C$, Rees K, Ebrahim S, et al. Fixed-dose combination therapy for the prevention of cardiovascular disease. Cochrane Database of Systematic Reviews. 2014;DOI: 10.1002/14651858.CDo09868.pub2.

35. Wald NJ, Law MR. A strategy to reduce cardiovascular disease by more than $80 \%$. BMJ. 2003;326:1419-23. 149. Anderson KM, Odell PM, Wilson PW, Kannel WB. Cardiovascular disease risk profiles. Am Heart J. 1990;121:293-8.

36. Cooney MT, Cooney HC, Dudina A, Graham IM. Assessment of cardiovascular risk. Current hypertension reports. 2010;12:38493.

37. Dent THS. Predicting the risk of coronary heart disease I. The use of conventional risk markers. Atherosclerosis. 2010;213:345-51. 
38. Sheridan SL, Crespo E. Does the routine use of global coronary heart disease risk scores translate into clinical benefits or harms? A systematic review of the literature. BMC health services research. 2008;8:60

39. Leyland $\mathrm{AH}$. Socioeconomic gradients in the prevalence of cardiovascular disease in Scotland: the roles of composition and context. Journal of Epidemiology and Community Health. 2005;59:799-803.

40. Pickett KE, Pearl M. Multilevel analyses of neighbourhood socioeconomic context and health outcomes: a critical review. Journal of Epidemiology and Community Health. 2001;55:111-22.

41. Stafford M, Bartley M, Mitchell R, Marmot $M$. Characteristics of individuals and characteristics of areas: investigating their influence on health in the Whitehall II study. Health and Place. 2001;7:117-29.

42. Barker DJP. The origins of the developmental origins theory. Journal of Internal Medicine. 2007;261:412-7. 188. Judge K, Bauld L. Learning from policy failure? Health Action Zones in England. European journal of public health. 2006;16(4):341-4.

43. Stafford M, Nazroo J, Popay JM, Whitehead $M$. Tackling inequalities in health: evaluating the New Deal for Communities initiative. Journal of Epidemiology and Community Health. 2008;62:298-304. 